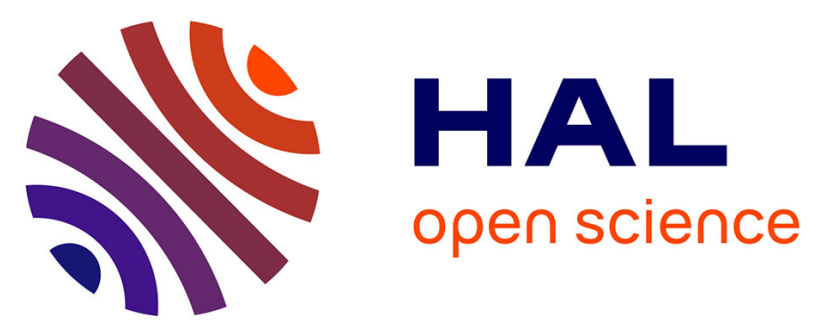

\title{
Two-stage hepatectomy for colorectal liver metastases: Pathologic response to preoperative chemotherapy is associated with second-stage completion and longer survival
}

François Quenet, Marie-Hélène Pissas, Hugo Gil, Lise Roca, Sébastien Carrere, Olivia Sgarbura, Philippe Rouanet, Hélène de Forges, Lakhdar Khellaf, Emmanuel Deshayes, et al.

\section{- To cite this version:}

François Quenet, Marie-Hélène Pissas, Hugo Gil, Lise Roca, Sébastien Carrere, et al.. Two-stage hepatectomy for colorectal liver metastases: Pathologic response to preoperative chemotherapy is associated with second-stage completion and longer survival. Surgery, 2019, 165 (4), pp.703-711. 10.1016/j.surg.2018.10.006 . hal-02448906

\section{HAL Id: hal-02448906 \\ https://hal.umontpellier.fr/hal-02448906}

Submitted on 22 Oct 2021

HAL is a multi-disciplinary open access archive for the deposit and dissemination of scientific research documents, whether they are published or not. The documents may come from teaching and research institutions in France or abroad, or from public or private research centers.
L'archive ouverte pluridisciplinaire HAL, est destinée au dépôt et à la diffusion de documents scientifiques de niveau recherche, publiés ou non, émanant des établissements d'enseignement et de recherche français ou étrangers, des laboratoires publics ou privés.

\section{(ㄷ)(1) $\$$}

Distributed under a Creative Commons Attribution - NonCommerciall 4.0 International 


\section{Two-stage hepatectomy for colorectal liver metastases: pathologic response to preoperative chemotherapy is associated with second-stage completion and longer survival}

François Quénet ${ }^{1 *}, \mathrm{MD}$, Marie-Hélène Pissas ${ }^{1 *}, \mathrm{MD}$, Hugo Gil ${ }^{2}, \mathrm{MD}$, Lise Roca ${ }^{3}, \mathrm{MSc}$, Sébastien Carrère ${ }^{1}, \mathrm{MD}$, Olivia Sgarbura ${ }^{1}, \mathrm{MD}$, Philippe Rouanet ${ }^{1}, \mathrm{MD}, \mathrm{PhD}$, Hélène de Forges $^{4}, \mathrm{PhD}$, Lakhdar Khellaf ${ }^{2}, \mathrm{MD}$, Emmanuel Deshayes ${ }^{5}, \mathrm{MD}$, Marc Ychou ${ }^{6}, \mathrm{MD}, \mathrm{PhD}$, Frédéric Bibeau ${ }^{2,7}, \mathrm{MD}, \mathrm{PhD}$.

${ }^{1}$ Surgical oncology Department, Institut régional du Cancer de Montpellier (ICM), Univ. Montpellier, Montpellier, France

${ }^{2}$ Anatomopathology Department, Institut régional du Cancer de Montpellier (ICM), Univ. Montpellier, Montpellier, France

${ }^{3}$ Biometrics Unit, Institut régional du Cancer de Montpellier (ICM), Univ. Montpellier, Montpellier, France

${ }^{4}$ Clinical research Unit, Institut régional du Cancer de Montpellier (ICM), Univ. Montpellier, Montpellier, France

${ }^{5}$ Nuclear Medicine Department, Institut régional du Cancer de Montpellier (ICM), Univ. Montpellier, Montpellier, France

${ }^{6}$ Medical Oncology Department, Institut régional du Cancer de Montpellier (ICM), Univ. Montpellier, Montpellier, France

${ }^{7}$ Anatomopathology Department, Centre Hospitalier Universitaire de Caen, Caen, France

* These two authors are co-first authors

\section{Corresponding author:}

Dr François Quénet

Surgical oncology Department, Institut régional du Cancer de Montpellier (ICM)

208 Avenue des Apothicaires, 34298 Montpellier, France

E-mail: François.quenet@icm.unicancer.fr

Tel: +33467613103

Fax: +33467613703

Running head: Pathologic response and longer survival 


\section{ABSTRACT}

\section{Background}

Two-stage hepatectomy (TSH) of bilobar colorectal liver metastases (CRLM) is widely used and shows encouraging survival results. However, the risk of drop-out after the first-stage remains high and associated with poor survival. The objective of our study was to evaluate the factors associated with long-term survival based on the pathologic response to preoperative systemic chemotherapy in CRLM patients who underwent TSH.

\section{Methods}

The pathologic response to preoperative chemotherapy and its effect on second-stage completion and survival were retrospectively evaluated in 67 patients treated between 2003 and 2013.

\section{Results}

Fifty-six patients underwent TSH for initially non-resectable CRLM. Chemotherapy was combined with a biotherapy in 32 cases. The Tumor Regression Grade (TRG), modified-TRG and Blazer grade were used to classify patients as responders (TRG and mTRG 1-3, Blazer 01) or non-responders (TRG and mTRG 4-5, Blazer 2) after the first stage. Tumor response in the three classifications was associated with second-stage completion (TRG 1-3: OR=4.01 95\% CI: 1.12-14.36 $p=0.033$; mTRG 1-3: OR=3.8 95\% CI:1.13-12.6 $p=0.03$; Blazer 0-1: $\mathrm{OR}=5.45$ 95\% CI: 1.66-17.85 $p=0.005)$. Triple chemotherapy was also associated with responders. The median overall survival of responders was significantly higher (Blazer 0-1: 42.9 months versus Blazer 2: 20.1 months $p=0.018$; TRG 1-3: 42.9 months versus TRG 4-5: 25.1 months, $p=0.04)$.

\section{Conclusion}

A pathologic response to chemotherapy is associated with second-stage completion and 
longer survival. Furthers studies are needed to try to early identify the patients for whom the benefit of the second surgical stage is less straightforward.

Keywords: colorectal cancer, liver metastases, two-stage resection, pathologic response, survival 


\section{INTRODUCTION}

Liver metastases occur in approximately $50 \%$ of patients affected by colorectal cancer and are the most common cause of death in this population ${ }^{1,2}$. Recent advances in multidisciplinary approaches have changed the prognosis of patients with colorectal liver metastases (CRLM) $)^{3,4}$ and technical improvements such as the two-stage hepatectomy (TSH) now allow a higher number of patients with CRLM to be eligible for surgery ${ }^{5,6}$.

The TSH strategy is widely used since the $2000 \mathrm{~s}^{6}$ for patients with initially unresectable metastases, becoming resectable after neoadjuvant chemotherapy. This potentially-curative strategy is associated with longer overall survival for patients who completed the two surgical stages. However, the risk of drop-out before the second stage is high, mainly due to disease progression $^{7}$. Patients who drop-out before the second surgical stage have poorer survival rates, close to those obtained in unresectable patients, and surgery may thus be inappropriate $^{7,8}$. Studies have suggested that increased exposure to chemotherapy prior to the first hepatectomy may predict failure to complete the second surgical stage ${ }^{9}$ and that the pathologic response to intensive preoperative chemotherapy is a favourable prognostic factor $^{10}$. However, the prognostic impact of the pathologic response to systemic chemotherapy is probably still underestimated. We thus conducted a retrospective study to demonstrate a possible correlation between the pathologic response to preoperative chemotherapy and survival in CRLM patients who underwent TSH. The objective of our study was to evaluate the factors associated with the completion of the second surgical stage, and, consequently, of progression-free and overall survival, based on the pathologic response to systemic chemotherapy administered preoperatively.

\section{PATIENTS AND METHODS}




\section{Patients}

From January 2003 to January 2013, 899 patients were treated for CRLM in our institution. Among these, patients with multiple, bilobar CRLM initially considered unresectable with a one-stage procedure, and who underwent at least the first stage of a planned TSH, were retrospectively selected for analysis on an intent-to-treat basis. Initial unresectability was defined as the inability to resect all metastases with tumor-free margins while saving a sufficient remnant liver volume to prevent postoperative liver failure. A sufficient remnant liver volume was defined as $30 \%$ of the residual liver parenchyma on CT-scan ${ }^{11}$ or by estimation of the future remnant liver function with ${ }^{99 \mathrm{~m}} \mathrm{Tc}-\mathrm{mebrofenin}$ 3D SPECT-CT. Patients with a ${ }^{99 \mathrm{~m}} \mathrm{Tc}$-mebrofenin clearance rate $<2.69 \% / \mathrm{min} / \mathrm{m}^{2}$ were considered at high risk of postoperative liver failure ${ }^{12}$.

Patients with metachronous metastases diagnosed at least three months after primary tumor diagnosis were also included. Patients with unplanned repeated hepatic resection for recurrence, who underwent a one-stage resection, or who presented with an unresectable extrahepatic abdominal disease were excluded from the study. A limited lung metastatic involvement was not considered a contraindication for hepatic resection. The protocol was approved by the local ethics committee review board. The study was conducted according to the Declaration of Helsinki and European Good Clinical Practice requirements. Patients were informed that their clinical and scientific data could be used for scientific purpose prior to their care in our institution.

\section{Preoperative chemotherapy and therapeutic strategy}

All patients were treated with intensive chemotherapy before liver resection, with oxaliplatin, irinotecan, 5-fluorouracil (5-FU), leucovorin and capecitabine (5-FU oral form) as doublet or triplet regimens. From 2008, a biotherapy (bevacizumab, cetuximab or panitumumab) ${ }^{13-15}$ 
was frequently added, depending on the $R A S$ status. The Response Evaluation Criteria In Solid Tumor (RECIST) evaluation was used to select patients responding to preoperative chemotherapy ${ }^{16}$.

\section{Surgery}

During the first operative stage, the future remnant liver was cleared from tumor tissue using wedge resection and/or anatomical resection and/or radiofrequency ablation. Resection of the primary colorectal tumor was performed concomitantly if the surgical liver procedure was not too important and in case the primary tumor was symptomatic. To prevent tumor progression, interval chemotherapy was for most patients administered between the two surgical stages. A portal vein ligation or embolization was performed to prevent postoperative liver failure according to volumetric CT-scan and mebrofenin hepatoscintigraphy data. Resection was mostly a right hepatectomy to achieve a curative resection. Postoperative morbidity at 30 days was graded according to the Clavien-Dindo classification ${ }^{17}$. Postoperative mortality was defined as death occurring within 90 days following surgery.

\section{Pathologic response}

All tumor metastases were sampled for pathology examination. Three- $\mu$ m thick sections of formalin-fixed paraffin-embedded tissues were mounted on SuperFrost Plus glass slides (Menzel, GmbH, Germany) deparaffinized before Hematein-Eosin-Saffron (HES) staining.

Three pathologists with hepatobiliary expertise and blinded to the clinical data evaluated the response in all resected metastases, using the Tumor Regression Grade (TRG), the modified TRG and the Blazer classification ${ }^{10,18,19}$. Challenging evaluation cases were reviewed jointly for final consensus. Patients were classified as pathologic responders (TRG and mTRG 1-3, Blazer 0-1) or non-responders (TRG and mTRG 4-5, Blazer 2) after the first stage. The mean 
percentage of residual tumor cells and regression features in the different metastases were used to define the pathologic response. Differentiation, tumour size, number of metastases and resection margins were also reported for each patient.

\section{Statistical analyses}

Patients' characteristics were compared using the $\chi 2$ or the Fisher's exact tests for discrete variables. The Student's t-test and Wilcoxon rank-sum test were used for continuous variables. Factors associated with second-stage completion were analysed using univariate and multivariate logistic regression models. Factors significant at the $p<0.05$ level in the univariate analysis and the appropriate pathologic response variable were included in the classical multivariate model, validated using a stepwise automatic method. Survival rates were estimated from the first surgery until the event of interest, death of any cause for OS and recurrence for RFS, using the Kaplan-Meier method, and compared using a log-rank test. Median survival was presented with its $95 \%$ confidence interval (95\% CI). Patients lost to follow-up were censored at the last documented visit, and those who died without recurrence at the date of death. All statistical analyses were performed using the STATA 11.0 software (StataCorp, College Station, Texas).

\section{RESULTS}

\section{Patients' characteristics}

TSH strategy was planned for 67 patients, among whom 11 were excluded because of the lack of pathological sample: 8 because they only had radiofrequency and 3 because the samples were not found (Figure 1 and Table 1). The median age was 59 years (range: 38-77) and there were $25(44.6 \%)$ women. The primary tumor site was colon in $80.4 \%$ cases. All CRLM were bilobar at diagnosis, and $90.9 \%$ were synchronous. The median time from initial diagnosis 
and occurrence of metachronous metastases was 18.3 months (95\% CI: 11.8-28.7). RAS was mutated in $30.6 \%$ patients and $25.5 \%$ had a carcinoembryogenic antigen (CEA) level $>200 \mathrm{ng} / \mathrm{mL}$.

\section{Preoperative chemotherapy}

All patients received downstaging chemotherapy. The median number of cycles was 8 (4-25). A doublet regimen, FOLFIRI (5FU+irinotecan) or FOLFOX (5FU+oxaliplatine) was administered to $60.7 \%$ patients and FOLFIRINOX (5FU+oxaliplatine+irinotecan) to $33.9 \%$ patients. A biotherapy was associated with chemotherapy for $55.3 \%$ patients.

\section{First-stage hepatectomy}

The median hospital stay was 11 days (6-162) (Table 2). A median of 3 (1-5) radiofrequency ablations and 1 (1-6) non-anatomical resection were performed. The median size of the largest metastasis resected was $18 \mathrm{~mm}(3-60)$. The primary colorectal tumor was resected during this first surgery in 22 patients (39.3\%). Postoperative grade $\geq 3$ morbidity at 30 days was reported in $8(14.3 \%)$ patients (Table 2), mainly hepatic abscesses $(n=3)$ and complications linked to the primary colorectal tumor $(n=3)$. There was no postoperative mortality at 90 days.

\section{Second-stage hepatectomy}

The TSH was completed for $35(62.5 \%)$ patients. Twenty-one patients dropped-out after the first surgical stage. The main reason was disease progression $(n=16)$, including hepatic $(n=14)$ or extra-hepatic $(n=1)$ progression, or both $(n=13)$. Two patients experienced severe complications after the first surgery (one rectal fistula and one abdominal wall complication) which prevented undergoing the second stage; one patient refused the second surgery, and 3 were lost to follow-up. 
The median time between the two surgical stages was 6 months (2-24), mainly due to our deliberate policy to administer systemic chemotherapy between the two stages. Interval chemotherapy was administered to $50(89.3 \%)$ patients, with a median of 6 cycles (4-20) (Table 1). Six patients (11\%) did not receive interval chemotherapy, mostly patients who had undergone radiofrequency ablations with non-anatomic resections. A portal vein embolization was reported in $17.6 \%$ patients. The median hospital stay was 11 days (5-49). A standard right hepatectomy was performed in $31.4 \%$ patients, and $23.4 \%$ underwent a right lobectomy (Table 2). Postoperative grade $\geq 3$ morbidity was reported in $6(17.1 \%)$ patients mainly hepatic abscesses $(n=3)$ and complications linked to the primary colorectal tumor $(n=2)$. Two patients died of disease progression within 90 days following the second stage. There was no postoperative mortality reported.

\section{Pathologic response}

A pathologic response (TRG, mTRG 1-3, and Blazer 1-0) was observed in $21(37.5 \%), 24$ (42.9\%), and $30(53.6 \%)$ patients, respectively (Table 3). Patients who completed the two stages were significantly better responders than those who dropped-out, according to the three classifications: $48.6 \%$ vs $19.0 \%, 54.3 \%$ vs $23.8 \%$ and $68.6 \%$ vs $28.6 \%$ responders vs nonresponders for the TRG, mTRG and Blazer, respectively.

The pathologic response was associated with second-stage completion according to the three classifications: TRG 1-3: OR=4.01; 95\% CI: 1.12-14.36; $p=0.033 ;$ mTRG 1-3: OR=3.8; $95 \%$ CI: $1.13-12.6 ; p=0.03$; Blazer $0-1: \mathrm{OR}=5.45 ; 95 \% \mathrm{CI}: 1.66-17.85 ; p=0.005$ in univariate analysis. In multivariate analysis, among the three classifications, only the Blazer grade was associated with second stage completion (Blazer 0/1: OR=5.42; 95\% CI: 1.53-19.15; $p=0.006)$, together with the initial number of metastases $\leq 5(\mathrm{OR}=4.06,95 \% \mathrm{CI}: 1.14-14.47$, $p=0.009)($ Table 4). 
The neoadjuvant FOLFIRINOX regimen was associated with a pathologic response according to the three classifications (TRG 1-3:73.7\% vs TRG 4-5: 26.3\%; $p<0.001$; mTRG 1-3: 73.7\% vs mTRG 4-5: 26.3\%; $p<0.0001$; Blazer 0-1: 84.2\% vs Blazer 2: 15.8\%; $p=0.002$ ) (Table 5).

\section{Survival}

After a median follow-up of 66 months, the median overall survival (OS) of the whole population was 39 months (95\% CI: 25.1-42.9), with 3-year and 5-year OS rates of 46.7\% (95\% CI: 32.6-59.6) and 17.1\% (95\% CI: 7.1-30.8). In patients who completed TSH, the median OS was significantly higher than that of patients who did not: 50 months $(95 \% \mathrm{CI}$ : 36.2-59.3) versus 18.4 months (95\% CI: 12.0-22.2) respectively, with a 3-year OS rate of $71 \%$ (95\% CI: $51.4-83.8)$ versus $9.5 \%$ (95\% CI: 1.6-26.1), hazard ratio (HR)=0.17 (95\% CI: 0.08-0.35, $p<0.001$ ) (Figure 2). The median relapse-free survival (RFS) of patients who completed the two stages ( $\mathrm{n}=43)$ was 16.9 months (95\% CI: 14.5-21) (Figure 2). The median OS was significantly higher in responders according to the TRG and Blazer classifications: Blazer 0-1: 42.9 months versus Blazer 2: 20.1 months, $\mathrm{HR}=2.14$ (95\% CI: 1.13-4.04), $p=0.018$, and TRG 1-3: 42.9 months versus TRG 4-5: 25.1 months, HR=2.08 (95\% CI: 1.034.19), $p=0.04$ (Figure 3).

\section{DISCUSSION}

The present study is, to our knowledge, the first to demonstrate a direct correlation between a favorable pathologic response to chemotherapy and second-stage completion, and thus longer survival. In unresectable CRLM patients, previous studies have shown that a major pathologic response after preoperative treatment was a favorable prognostic factor ${ }^{10,18,19}$. Yet, its importance is not fully taken into account when taking therapeutic decisions. Among the three classifications, the $\mathrm{TRG}^{18}$ considers fibrosis as a characteristic feature of cellular response, 
whereas the $\mathrm{mTRG}^{19}$ also takes into account the infarct-like necrosis (ILN); the Blazer score ${ }^{10}$ is exclusively based on the percentage of residual tumor cells relative to the total tumor area, whatever the type of regression, and may thus be more efficient to evaluate the impact of intensive induction treatments. Probably because of that reason, the pathologic response was higher assessed with the Blazer score than with both the TRG and mTRG in our series, and it was the only classification associated with second-stage completion in multivariate analysis. Our study also allowed identification of patients treated with FOLFIRINOX as better responders than those treated with the standard regimen. Correlatively, Ychou et al. showed that this triplet systemic chemotherapy was associated with a better response, higher resectability and OS rates ${ }^{20}$.

Very few series have evaluated the impact of the pathologic response in the setting of TSH strategies. Faitot et al. showed that the pathologic response was associated with clinical outcome but not with TSH feasibility, contrary to our study ${ }^{21}$. Another study, Mentha et al., showed in 22 CRLM patients treated with neoadjuvant therapy and TSH that a "dangerous halo" in the pathologic findings was a bad prognosis factor but didn't correlate the intensity of the pathologic response to survival ${ }^{22}$. Recently, Pietrantonio et al. showed that bevacizumab induced significant better pathological response rates and complete responses compared with cetuximab even if OS was not significantly different ${ }^{23}$. Moreover, a significant correlation with pathological response was found between the number of resected metastases and bevacizumab allocation.

Numerous studies have suggested that regenerative growth factor levels increased immediately after the first-stage hepatectomy and contributed to tumor recurrence ${ }^{24-26}$. In this context, administering interval chemotherapy allowed a longer period of natural liver regeneration while preventing tumor progression. It thus was our deliberate policy to administer interval systemic chemotherapy, although its benefits are still controversial. 
Tanaka et $a .^{27}$ showed decreased tumour growth and growth factor expression with perioperative chemotherapy, while Muratore et $a l .{ }^{28}$ showed no benefit of interval chemotherapy on disease progression between the two surgical stages.

The main drawback of the TSH strategy is that more than $30 \%$ patients drop-out after the first-stage procedure (36\% patients in our study $)^{7,8}$. They have a poor prognosis, with survival no longer than that of patients undergoing chemotherapy alone ${ }^{7}$. The median OS of patients who only underwent the first stage was of 18.4 months (95\% CI: 12-22.2) compared to almost 50 months for those who completed the second stage; 3-year OS rates were $9.5 \%$, and $71 \%$, respectively. Completion of the whole procedure allows a similar benefit than that of the single stage reported in patients with initially resectable liver metastases ${ }^{29}$. It was shown that the main cause of drop-out is disease progression between the two stages ${ }^{7}$. It is thus essential to identify patients who will not reach the second surgery ${ }^{30}$. Several studies have identified predictive factors of drop-out ${ }^{8,9,30-32}$, among which major postoperative complications after the first stage ${ }^{31}$, older age, CEA level $>200 \mathrm{ng} / \mathrm{ml}$ before portal vein embolization, 3 or more tumours in the future remnant liver ${ }^{8}$, high number of metastases, and increased exposure to chemotherapy prior to the first hepatectomy ${ }^{8}$. Mise et al. showed that a $R A S$ mutation should be taken into account to predict response to chemotherapy ${ }^{33}$. In this study, a pathologic response was more common in patients with wild-type $R A S$ compared with patients with $R A S$ mutations. Passot et al. showed that the $R A S$ mutation independently predicts the oncologic efficacy of $\mathrm{TSH}^{34}$.

A pathologic response was shown to be a strong prognostic factor after preoperative chemotherapy and surgical resection of $\mathrm{CRLM}^{35,36}$ and, in another field, of colorectal distant metastasis such as peritoneal carcinomatosis ${ }^{37}$. However, its use for treatment decision remains limited. Our study shows some limitations as it was retrospective and monocentric, 
and with a relatively limited number of patients. However, it is the first to show a significant correlation between a pathologic response to chemotherapy and second stage completion and consecutively, a better survival and, considering the design limitations, proofs of these correlations seem quite robust. We hope it to be a first step towards further investigations correlating histologic and radiologic findings. Among these, identifying non-responders patients before the first surgical step, which is unfortunately not yet possible, would allow sparing some patients from a not necessarily-needed surgery.

\section{CONCLUSION}

A pathologic response to preoperative chemotherapy after the first-stage hepatectomy is associated with completion of the second surgical stage and of longer survival. The accurate assessment of the pathologic response to induction treatments represents an important contribution from pathologists for treatment decision for these patients, and may allow avoiding resections for patients for whom the TSH strategy benefit seems less straightforward.

\section{Acknowledgments}

The authors thank the patients and their families. They also thank the Drs. Emmanuelle Samalin, Fabienne Portales, and Thibault Mazard for their participation to the study, and Pr. Bernard Saint-Aubert for providing expertise and interesting discussions all along the project. This research was supported by the SIRIC Montpellier Cancer Grant INCa_Inserm_DGOS_12553.

\section{Authors' contributions}

Study design: FQ, FB.

Collection of data: FQ, MHP, HG, LK, SC, OS, PR, ED, MY, FB.

Analysis and interpretation of data: LR, FQ, FB, MHP.

Drafting of the manuscript: FQ, MHP, HF, FB 
Revising critically the manuscript: FQ, MHP, FB, HF, OS, PR, SC, LR

Final validation of the manuscript: FQ, MHP, HG, LR, SC, OS, PR, HF, LK, ED, MY, FB.

Disclosure: All the other authors have no conflict of interest to disclose in relation with the present study. 


\section{References}

1. Stangl, R., Altendorf-Hofmann, A., Charnley, R. M. \& Scheele, J. Factors influencing the natural history of colorectal liver metastases. Lancet 343, 1405-1410 (1994).

2. Siegel, R. L., Miller, K. D. \& Jemal, A. Cancer statistics, 2016. CA. Cancer J. Clin. 66, 7-30 (2016).

3. Kopetz, S. et al. Improved survival in metastatic colorectal cancer is associated with adoption of hepatic resection and improved chemotherapy. J. Clin. Oncol. 27, 3677-3683 (2009).

4. de Haas, R. J. et al. Impact of expanding criteria for resectability of colorectal metastases on short- and long-term outcomes after hepatic resection. Ann. Surg. 253, 1069-1079 (2011).

5. Adam, R. et al. Patients with initially unresectable colorectal liver metastases: is there a possibility of cure? J. Clin. Oncol. 27, 1829-1835 (2009).

6. Adam, R., Laurent, A., Azoulay, D., Castaing, D. \& Bismuth, H. Two-Stage Hepatectomy: A Planned Strategy to Treat Irresectable Liver Tumors. Ann. Surg. 232, $777-785$ (2000).

7. Lam, V. W. T. et al. A systematic review of two-stage hepatectomy in patients with initially unresectable colorectal liver metastases. HPB Hepato Pancreato Biliary 15, 483491 (2013).

8. Tsai, S. et al. Two-stage strategy for patients with extensive bilateral colorectal liver metastases. HPB Hepato Pancreato Biliary 12, 262-269 (2010).

9. Giuliante, F. et al. Tumor Progression During Preoperative Chemotherapy Predicts Failure to Complete 2-Stage Hepatectomy for Colorectal Liver Metastases: Results of an Italian Multicenter Analysis of 130 Patients. J. Am. Coll. Surg. 219, 285-294 (2014). 
10. Blazer, D. G. et al. Pathologic Response to Preoperative Chemotherapy: A New Outcome End Point After Resection of Hepatic Colorectal Metastases. J. Clin. Oncol. 26, 5344$5351(2008)$

11. Vauthey, J.-N. et al. Recurrence and Outcomes Following Hepatic Resection, Radiofrequency Ablation, and Combined Resection/Ablation for Colorectal Liver Metastases. Ann. Surg. 239, 818-827 (2004).

12. Chapelle, T. et al. Future remnant liver function estimated by combining liver volumetry on magnetic resonance imaging with total liver function on $(99 \mathrm{~m}) \mathrm{Tc}-\mathrm{mebrofenin}$ hepatobiliary scintigraphy: can this tool predict post-hepatectomy liver failure? $H P B$ Hepato Pancreato Biliary 18, 494-503 (2016).

13. Cremolini, C. et al. FOLFOXIRI plus bevacizumab versus FOLFIRI plus bevacizumab as first-line treatment of patients with metastatic colorectal cancer: updated overall survival and molecular subgroup analyses of the open-label, phase 3 TRIBE study. Lancet Oncol. 16, 1306-1315 (2015).

14. Folprecht, G. et al. Survival of patients with initially unresectable colorectal liver metastases treated with FOLFOX/cetuximab or FOLFIRI/cetuximab in a multidisciplinary concept (CELIM study). Ann. Oncol. 25, 1018-1025 (2014).

15. Loupakis, F. et al. Histopathologic evaluation of liver metastases from colorectal cancer in patients treated with FOLFOXIRI plus bevacizumab. Br. J. Cancer 108, 2549-2556 (2013).

16. Eisenhauer, E. A. et al. New response evaluation criteria in solid tumours: revised RECIST guideline (version 1.1). Eur. J. Cancer 45, 228-247 (2009).

17. Dindo, D., Demartines, N. \& Clavien, P.-A. Classification of Surgical Complications. Ann. Surg. 240, 205-213 (2004). 
18. Rubbia-Brandt, L. et al. Importance of histological tumor response assessment in predicting the outcome in patients with colorectal liver metastases treated with neoadjuvant chemotherapy followed by liver surgery. Ann. Oncol. 18, 299-304 (2007).

19. Chang, H. H. L., Leeper, W. R., Chan, G., Quan, D. \& Driman, D. K. Infarct-like necrosis: a distinct form of necrosis seen in colorectal carcinoma liver metastases treated with perioperative chemotherapy. Am. J. Surg. Pathol. 36, 570-576 (2012).

20. Ychou, M. et al. A randomized phase II trial of three intensified chemotherapy regimens in first-line treatment of colorectal cancer patients with initially unresectable or not optimally resectable liver metastases. The METHEP trial. Ann. Surg. Oncol. 20, 42894297 (2013).

21. Faitot, F. et al. Feasibility and survival of 2-stage hepatectomy for colorectal metastases: Definition of a simple and early clinicopathologic predicting score. Surgery $\mathbf{1 5 7}, 444-453$ (2015).

22. Mentha, G. et al. Dangerous halo after neoadjuvant chemotherapy and two-step hepatectomy for colorectal liver metastases. Br. J. Surg. 96, 95-103 (2009).

23. Pietrantonio, F. et al. Pathological response after neoadjuvant bevacizumab- or cetuximab-based chemotherapy in resected colorectal cancer liver metastases. Med. Oncol. Northwood Lond. Engl. 32, 182 (2015).

24. Harun, N., Nikfarjam, M., Muralidharan, V. \& Christophi, C. Liver Regeneration Stimulates Tumor Metastases. J. Surg. Res. 138, 284-290 (2007).

25. Lukomska, B., Dluzniewska, J., Polanski, J. \& Zajac, L. Expression of growth factors in colorectal carcinoma liver metastatic patients after partial hepatectomy: implications for a functional role in cell proliferation during liver regeneration. Comp. Hepatol. 3, S52 (2004). 
26. Elias, D. et al. During liver regeneration following right portal embolization the growth rate of liver metastases is more rapid than that of the liver parenchyma. Br. J. Surg. 86, 784-788 (1999).

27. Tanaka, K. et al. Two-stage hepatectomy with effective perioperative chemotherapy does not induce tumor growth or growth factor expression in liver metastases from colorectal cancer. Surgery 153, 179-188 (2013).

28. Muratore, A. et al. Chemotherapy between the first and second stages of a two-stage hepatectomy for colorectal liver metastases: should we routinely recommend it? Ann. Surg. Oncol. 19, 1310-1315 (2012).

29. Faitot, F. et al. Two-stage hepatectomy versus 1-stage resection combined with radiofrequency for bilobar colorectal metastases: a case-matched analysis of surgical and oncological outcomes. Ann. Surg. 260, 822-827; discussion 827-828 (2014).

30. Turrini, O. et al. Two-stage hepatectomy: Who will not jump over the second hurdle? Eur. J. Surg. Oncol. 38, 266-273 (2012).

31. Brouquet, A. et al. High Survival Rate After Two-Stage Resection of Advanced Colorectal Liver Metastases: Response-Based Selection and Complete Resection Define Outcome. J. Clin. Oncol. 29, 1083-1090 (2011).

32. Narita, M. et al. Two-stage hepatectomy for multiple bilobar colorectal liver metastases. Br. J. Surg. 98, 1463-1475 (2011).

33. Mise, Y. et al. RAS mutations predict radiologic and pathologic response in patients treated with chemotherapy before resection of colorectal liver metastases. Ann. Surg. Oncol. 22, 834-842 (2015).

34. Passot, G. et al. Predictors of Safety and Efficacy of 2-Stage Hepatectomy for Bilateral Colorectal Liver Metastases. J. Am. Coll. Surg. 223, 99-108 (2016).

35. Adam, R. et al. Complete pathologic response after preoperative chemotherapy for colorectal liver metastases: myth or reality? J. Clin. Oncol. 26, 1635-1641 (2008). 
36. Gruenberger, T., Arnold, D. \& Rubbia-Brandt, L. Pathologic response to bevacizumabcontaining chemotherapy in patients with colorectal liver metastases and its correlation with survival. Surg. Oncol. 21, 309-315 (2012).

37. Passot, G. et al. Pathological response to neoadjuvant chemotherapy: a new prognosis tool for the curative management of peritoneal colorectal carcinomatosis. Ann. Surg. Oncol. 21, 2608-2614 (2014).

38. Torzilli, G. et al. One-stage ultrasonographically guided hepatectomy for multiple bilobar colorectal metastases: a feasible and effective alternative to the 2-stage approach. Surgery 146, 60-71 (2009).

39. Viganò, L. et al. Drop-out between the two liver resections of two-stage hepatectomy. Patient selection or loss of chance? Eur. J. Surg. Oncol. 42, 1385-1393 (2016). 


\section{Figure legends}

\section{Figure 1}

Flowchart of the study

\section{Figure 2}

A: Overall survival in patients who completed or did not complete the two-stage resection;

B: Relapse-free survival of patients who completed the second stage.

\section{Figure 3}

Overall survival depending on the pathological response, according to the TRG (A), mTRG (B) and Blazer (C) classifications. A: TRG classification: responders (TRG 1,2,3) versus nonresponders; B : mTRG classification: responders (mTRG 1,2,3) versus non-responders $(4,5)$; C : Blazer classification: responders (Blazer 0,1) versus non-responders (Blazer 2).

\section{Tables}

Table 1: Patients' characteristics

Table 2: Surgical characteristics of the first and second stages

Table 3: Patients" and tumor characteristics, and histologic response in the "first-stage only" and the "two-stages completed" groups

Table 4: Factors associated with second-stage completion (uni- and multivariate analyses)

Table 5: Correlation between the neoadjuvant FOLFIRINOX regimen and the pathologic response 
Table 1: Patients' characteristics

\begin{tabular}{|c|c|c|}
\hline Patients' characteristics & & $n=56$ \\
\hline Age (years) & med (range) & $59(38-77)$ \\
\hline $\begin{array}{l}\text { Sex, } \mathrm{n}(\%) \\
\text { Male } \\
\text { Female }\end{array}$ & $n(\%)$ & $\begin{array}{l}31(55.4) \\
25(44.6)\end{array}$ \\
\hline $\begin{array}{l}\text { Site of primary tumor } \\
\text { Colon } \\
\text { Rectal }\end{array}$ & $n(\%)$ & $\begin{array}{l}45(80.4) \\
11(19.6)\end{array}$ \\
\hline $\mathrm{N}+$ stage & $n(\%)$ & $42(75.0)$ \\
\hline $\begin{array}{l}\text { Metastases, } \\
\text { Synchronous } \\
\text { Metachronous } \\
\text { Missing } \\
\end{array}$ & $n(\%)$ & $\begin{array}{c}50(90.9) \\
5(9.1) \\
1 \\
\end{array}$ \\
\hline $\begin{array}{l}\text { Initial number of metastases } \\
\quad 0-5 \\
5-10 \\
>10 \\
\quad \text { Missing }\end{array}$ & $n(\%)$ & $\begin{array}{c}28(50.9) \\
7(12.7) \\
20(36.4) \\
1 \\
\end{array}$ \\
\hline $\begin{array}{l}\text { Neoadjuvant chemotherapy regimens } \\
\text { Doublet therapy (Folfox or Folfiri) } \\
\text { Triplet therapy (Folfirinox) } \\
\text { Biotherapy } \\
\text { Bevacizumab } \\
\text { Cetuximab } \\
\text { Panitumumab } \\
\text { Missing }\end{array}$ & $n(\%)$ & $\begin{array}{c}56(100) \\
34(60.7) \\
19(33.9) \\
31(55.3) \\
14(25) \\
16(28.6) \\
1(1.5) \\
3\end{array}$ \\
\hline $\begin{array}{l}\text { Number of cycles, } \\
\text { Missing }\end{array}$ & med (range) & $\begin{array}{c}8(4-25) \\
5 \\
\end{array}$ \\
\hline $\begin{array}{l}\text { Interval chemotherapy regimens } \\
\text { Doublet therapy (Folfox or folfiri) } \\
\text { Triplet therapy (Folfirinox) } \\
\text { Biotherapy } \\
\text { Number of cycles, }\end{array}$ & med (range) & $\begin{array}{c}50(89.3) \\
42(75) \\
6(10.7) \\
37(66.1) \\
6(4-20) \\
\end{array}$ \\
\hline $\begin{array}{l}\text { Preoperative CEA plasma level }(\mathrm{ng} / \mathrm{ml}) \\
\quad>200 \\
\text { Missing }\end{array}$ & $n(\%)$ & $\begin{array}{c}13(25.5) \\
5\end{array}$ \\
\hline $\begin{array}{l}\text { RAS status } \\
\text { Mutated } \\
\text { Missing }\end{array}$ & $n(\%)$ & $\begin{array}{c}15(30.6) \\
7\end{array}$ \\
\hline
\end{tabular}

CEA: Carcinoembryonic antigen 
Table 2: Surgical characteristics of the first and second stages

\begin{tabular}{|c|c|c|}
\hline First-stage perioperative characteristics & & $n=56$ \\
\hline Length of stay (days) & med (range) & $11[6-162]$ \\
\hline Associated resection of primary tumor & $n(\%)$ & $22(39.3)$ \\
\hline $\begin{array}{l}\text { Side of hepatic clearance resection } \\
\text { Right } \\
\text { Left } \\
\text { Right }+ \text { Left }\end{array}$ & $n(\%)$ & $\begin{array}{l}6(10.7) \\
40(71.4) \\
10(17.9)\end{array}$ \\
\hline Anatomic minor liver resection (segmentectomy) & $n(\%)$ & $15(22.3)$ \\
\hline $\begin{array}{l}\text { Wedge resection } \\
\text { Median number per patient }\end{array}$ & $\begin{array}{l}n(\%) \\
\text { med (range) }\end{array}$ & $\begin{array}{c}46(82.1) \\
1[1-6]\end{array}$ \\
\hline $\begin{array}{l}\text { Radiofrequency, } \\
\text { Median number per patient }\end{array}$ & $\begin{array}{l}n(\%) \\
\text { med (range) }\end{array}$ & $\begin{array}{c}25(44.6) \\
3[1-5]\end{array}$ \\
\hline $\begin{array}{l}\text { Largest diameter of the resected metastases (mm), } \\
\text { Missing }\end{array}$ & med (range) & $\begin{array}{c}18[3-60] \\
2\end{array}$ \\
\hline $\begin{array}{l}\text { Resection margins (mm), } \\
\text { Contact margins with tumor, } \\
\text { Missing }\end{array}$ & $\begin{array}{l}\text { med (range) } \\
n(\%)\end{array}$ & $\begin{array}{c}2[1-25] \\
10(17.8) \\
10\end{array}$ \\
\hline Morbidity grade $\geq 3$ & $n(\%)$ & $8(14.3)$ \\
\hline Second-stage perioperative characteristics & & $\mathrm{n}=35$ \\
\hline Length of stay (days) & med (range) & $11[5-49]$ \\
\hline Delay between the 2 stages (months) & med (range) & $6.7[2.1-24.5]$ \\
\hline Portal embolization & $n(\%)$ & $6(17.6)$ \\
\hline Right hepatectomy $^{1}$ & $n(\%)$ & $11(31.4)$ \\
\hline Right lobectomy $^{2}$ & $n(\%)$ & $8(22.8)$ \\
\hline Left hepatectomy ${ }^{3}$ & $n(\%)$ & $2(5.7)$ \\
\hline Segmental resections $(\geq 2)^{*}$ & $n(\%)$ & $6(17.1)^{*}$ \\
\hline Morbidity grade $\geq 3$ & $n(\%)$ & $6(17.1)$ \\
\hline
\end{tabular}

${ }^{1}$ Segments 5 to $8 ;{ }^{2}$ Segments 4 to $8 ;{ }^{3}$ Segments 2 to 4

* Two patients had a single segmentectomy, but also had a right hepatectomy extended to segment 4 during the first surgical stage. 
Table 3: Patients" and tumor characteristics, and histologic response in the "first-stage only" and the "two-stages completed" groups

\begin{tabular}{|c|c|c|c|c|}
\hline n $(\%)$ & $\begin{array}{c}\text { First stage only } \\
\qquad \begin{array}{l}n=21\end{array}\end{array}$ & $\begin{array}{l}2 \text { stages completed } \\
n=35\end{array}$ & $\begin{array}{l}\text { Total } \\
\mathrm{n}=56\end{array}$ & $p$-value \\
\hline Age: $\begin{aligned} & <60 \\
& \geq 60\end{aligned}$ & $\begin{array}{c}8(38.1) \\
13(61.9)\end{array}$ & $\begin{array}{l}21(60) \\
14(40)\end{array}$ & $\begin{array}{l}29(51.8) \\
27(48.2)\end{array}$ & ns \\
\hline $\begin{array}{ll}\text { Sex } & \text { Male } \\
& \text { Female }\end{array}$ & $\begin{array}{l}13(61.9) \\
8(38.1)\end{array}$ & $\begin{array}{l}18(51.4) \\
17(48.6)\end{array}$ & $\begin{array}{l}31(55.4) \\
25(44.6)\end{array}$ & ns \\
\hline $\begin{array}{l}\text { Primary tumor localization } \\
\text { Colon } \\
\text { Rectum }\end{array}$ & $\begin{array}{l}17(81) \\
4(19)\end{array}$ & $\begin{array}{l}28(80) \\
7(20)\end{array}$ & $\begin{array}{l}45(80.4) \\
11(19.6)\end{array}$ & ns \\
\hline $\begin{array}{ll}\text { T stage } & \text { I/II } \\
& \text { III/IV } \\
& \mathrm{X}\end{array}$ & $\begin{array}{c}1(4.8) \\
16(76.2) \\
4(19)\end{array}$ & $\begin{array}{l}5(14.3) \\
28(80) \\
2(5.7)\end{array}$ & $\begin{array}{c}6(10.7) \\
44(78.6) \\
6(10.7)\end{array}$ & ns \\
\hline $\begin{array}{ll}\text { N stage } & \mathrm{N} 0 \\
& \mathrm{~N}+ \\
& N x\end{array}$ & $\begin{array}{c}2(9.5) \\
16(76.2) \\
3(14.3)\end{array}$ & $\begin{array}{c}9(25.7) \\
26(74.3) \\
0\end{array}$ & $\begin{array}{l}11(19.6) \\
42(75) \\
3(5.4)\end{array}$ & $p=0.03$ \\
\hline $\begin{array}{l}\text { Metastases } \\
\text { Number } \leq 5 \\
\text { Number }>5 \\
\text { Missing } \\
\text { Type } \\
\text { Synchronous } \\
\text { Metachronous } \\
\text { Missing }\end{array}$ & $\begin{array}{c}6(28.6) \\
15(71.4) \\
0 \\
19(90.5) \\
2(9.5) \\
0\end{array}$ & $\begin{array}{c}22(64.7) \\
12(35.3) \\
1 \\
31(91.2) \\
3(8.8) \\
1\end{array}$ & $\begin{array}{c}28(50.9) \\
27(49.1) \\
1 \\
50(90.9) \\
5(9.1) \\
1\end{array}$ & $\begin{array}{c}p<0.01 \\
\text { ns }\end{array}$ \\
\hline $\begin{array}{l}\text { CEA level } \\
\quad<200 \mathrm{ng} / \mathrm{dl} \\
>200 \mathrm{ng} / \mathrm{dl} \\
\text { Missing }\end{array}$ & $\begin{array}{c}13(76.5) \\
4(23.5) \\
4 \\
\end{array}$ & $\begin{array}{c}25(73.5) \\
9(26.5) \\
1 \\
\end{array}$ & $\begin{array}{l}38(74.5) \\
13(25.5) \\
5 \\
\end{array}$ & ns \\
\hline $\begin{array}{l}\text { RAS status } \\
\text { Mutated } \\
\text { Non-mutated } \\
\text { Missing } \\
\end{array}$ & $\begin{array}{c}5(29.4) \\
12(70.6) \\
4 \\
\end{array}$ & $\begin{array}{c}10(31.3) \\
22(68.8) \\
3 \\
\end{array}$ & $\begin{array}{c}15(30.6) \\
34(69.4) \\
7 \\
\end{array}$ & ns \\
\hline $\begin{array}{l}\text { Chemotherapy } \\
\text { Neoadjuvant } \\
\text { Interval }\end{array}$ & $\begin{array}{l}21(100) \\
19(90.5)\end{array}$ & $\begin{array}{l}32(91.4) \\
31(88.6)\end{array}$ & $\begin{array}{l}53(94.6) \\
50(89.3)\end{array}$ & $\begin{array}{l}\mathrm{ns} \\
\mathrm{ns}\end{array}$ \\
\hline $\begin{array}{l}\text { All-grade morbidity after the } \\
\text { first stage (Clavien-Dindo) }\end{array}$ & $6(28.6)$ & $9(25.7)$ & $15(26.8)$ & ns \\
\hline $\begin{array}{l}\text { Histologic response } \\
\text { TRG } \\
\text { Responders }(1 / 2 / 3) \\
\text { Non-responders }(4 / 5) \\
\text { mTRG } \\
\text { Responders }(1 / 2 / 3) \\
\text { Non-responders }(4 / 5) \\
\text { Blazer } \\
\text { Responders }(0 / 1) \\
\text { Non-responders }(2)\end{array}$ & $\begin{array}{c}4(19.0) \\
17(81.0) \\
\\
5(23.8) \\
16(76.2) \\
6(28.6) \\
15(71.4)\end{array}$ & $\begin{array}{l}17(48.6) \\
18(51.4) \\
19(54.3) \\
16(45.7) \\
24(68.6) \\
11(31.4)\end{array}$ & $\begin{array}{l}21(37.5) \\
35(62.5) \\
24(42.9) \\
32(57.1) \\
30(53.6) \\
26(46.4)\end{array}$ & $\begin{array}{l}p=0.045 \\
p=0.026 \\
p=0.004\end{array}$ \\
\hline
\end{tabular}

CEA: Carcinoembryonicantigen; TRG: Tumor Regression Grade; mTRG: modified TRG 
Table 4: Factors associated with second-stage completion (uni- and multivariate analyses)

\begin{tabular}{|l|c|c|c|}
\hline Univariate analysis & Odd ratio & $\mathbf{9 5 \%}$ CI & $\boldsymbol{p}$-value \\
\hline TRG $1 / 2 / 3$ & 4.01 & $1.12-14.36$ & $\mathbf{0 . 0 3 3}$ \\
\hline mTRG $1 / 2 / 3$ & 3.8 & $1.13-12.67$ & $\mathbf{0 . 0 3 0}$ \\
\hline Blazer 0/1 & 5.45 & $1.66-17.85$ & $\mathbf{0 . 0 0 5}$ \\
\hline $\begin{array}{l}\text { Initial number of } \\
\text { metastases } \leq 5\end{array}$ & 4.6 & $1.4-14.9$ & $\mathbf{0 . 0 1 1}$ \\
\hline Multivariate analysis & 5.42 & $1.53-19.15$ & $\mathbf{0 . 0 0 6}$ \\
\hline Blazer 0/1 & 4.06 & $1.14-14.47$ & $\mathbf{0 . 0 0 9}$ \\
\hline $\begin{array}{l}\text { Initial number of } \\
\text { metastases } \leq 5\end{array}$ & & & \\
\hline
\end{tabular}

TRG: Tumor Regression Grade; mTRG: modified TRG; 95\% CI: 95\% Confidence interval 
Table 5: Correlation between the neoadjuvant FOLFIRINOX regimen and the pathologic response

\begin{tabular}{|l|c|c|c|c|}
\hline & $\begin{array}{c}\text { No FOLFIRINOX } \\
\mathbf{n = 4 3}\end{array}$ & $\begin{array}{c}\text { FOLFIRINOX } \\
\mathbf{n = 2 4}\end{array}$ & $\begin{array}{c}\text { Total } \\
\mathbf{n = 6 7}\end{array}$ & $\boldsymbol{p}$-value \\
\hline TRG & & & & \\
$\quad$ Responders (1/2/3) & $7(18.9)$ & $14(73.7)$ & $21(37.5)$ & \\
$\quad \begin{array}{l}\text { Non-responders (4/5) } \\
\text { Missing }\end{array}$ & $30(81.1)$ & $5(26.3)$ & $35(62.5)$ & $\boldsymbol{p}<\mathbf{0 . 0 0 1}$ \\
& 6 & 5 & 11 & \\
\hline mTRG & & & & \\
Responders (1/2/3) & $10(27.0)$ & $14(73.7)$ & $24(42.9)$ & \\
Non-responders (4/5) & $27(73.0)$ & $5(26.3)$ & $32(57.1)$ & $\boldsymbol{p}=\mathbf{0 . 0 0 1}$ \\
Missing & 6 & 5 & 11 & \\
\hline Blazer & & & $30(53.6)$ & \\
Responders (0/1) & $14(37.8)$ & $16(84.2)$ & $26(46.4)$ & $\boldsymbol{p}=\mathbf{0 . 0 0 1}$ \\
Non-responders (2) & $23(62.2)$ & $3(15.8)$ & 11 & \\
Missing & 6 & 5 & \\
\hline
\end{tabular}

TRG: Tumor Regression Grade; mTRG: modified TRG 
Figure 1: Flowchart of the study

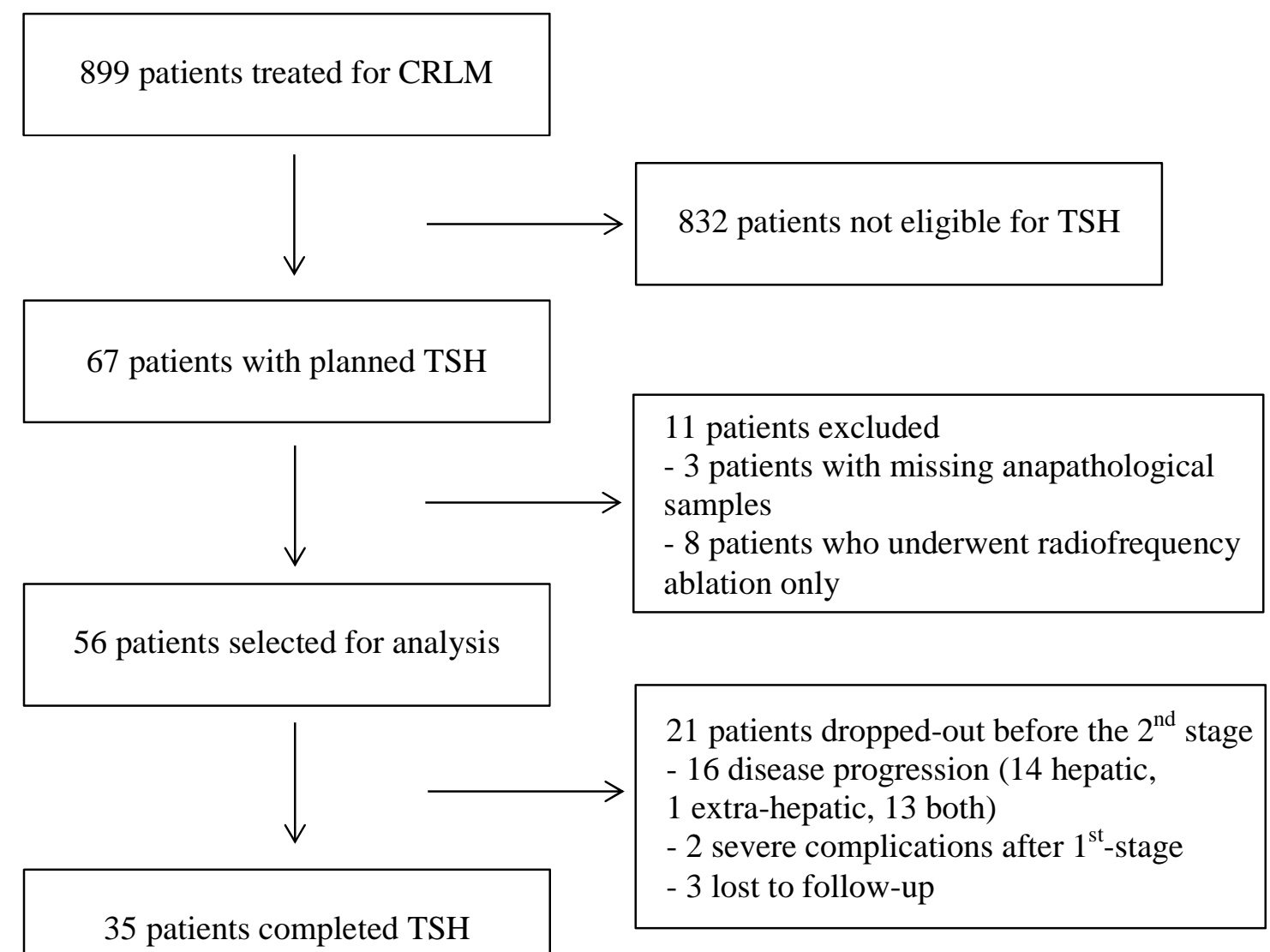




\section{Figure 2}

A. Overall survival (OS) in patients who completed or did not complete the two-stage resection

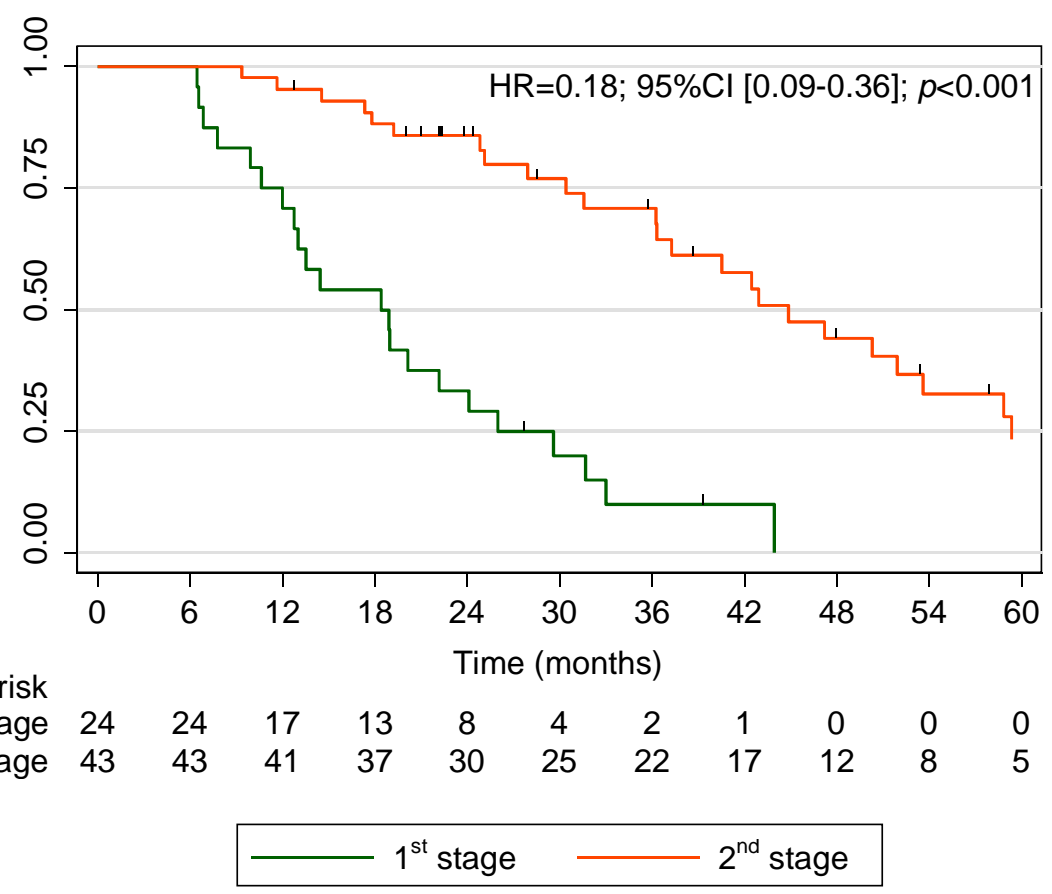

* OS was defined as the time between the date of first surgery to death. The Kaplan-Meier estimates of probabilities of $O S$ were estimated in all patients who completed or not the two-stage resection

B. Relapse-free survival (RFS) of patients who completed the second stage

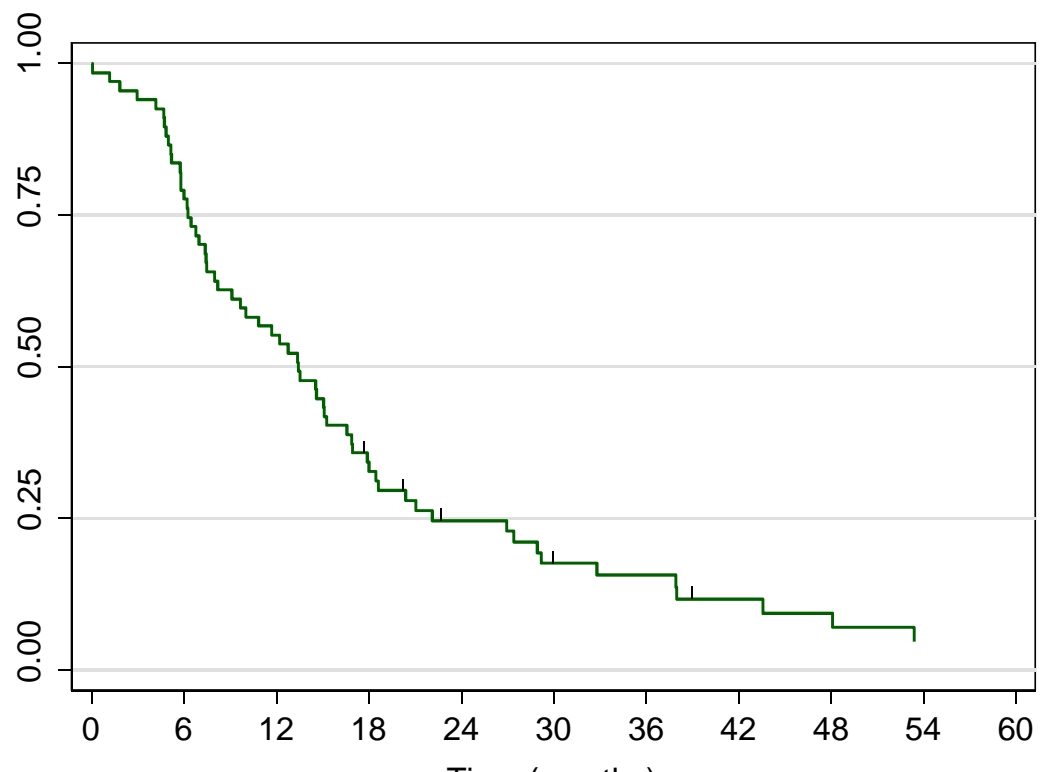

Number at risk

$\begin{array}{lllllllllll}67 & 53 & 37 & 21 & 14 & 9 & 8 & 5 & 4 & 2 & 2\end{array}$

* RFS was defined as the time between the date of first surgery to the relapse event. The Kaplan-Meier estimates of probabilities of RFS were estimated in all patients who completed the two-stage resection 
Figure 3: Overall survival depending on the pathological response, according to the TRG (A), mTRG (B) and Blazer (C) classifications.

A. TRG classification: responders (TRG 1,2,3) versus non-responders $(4,5)$

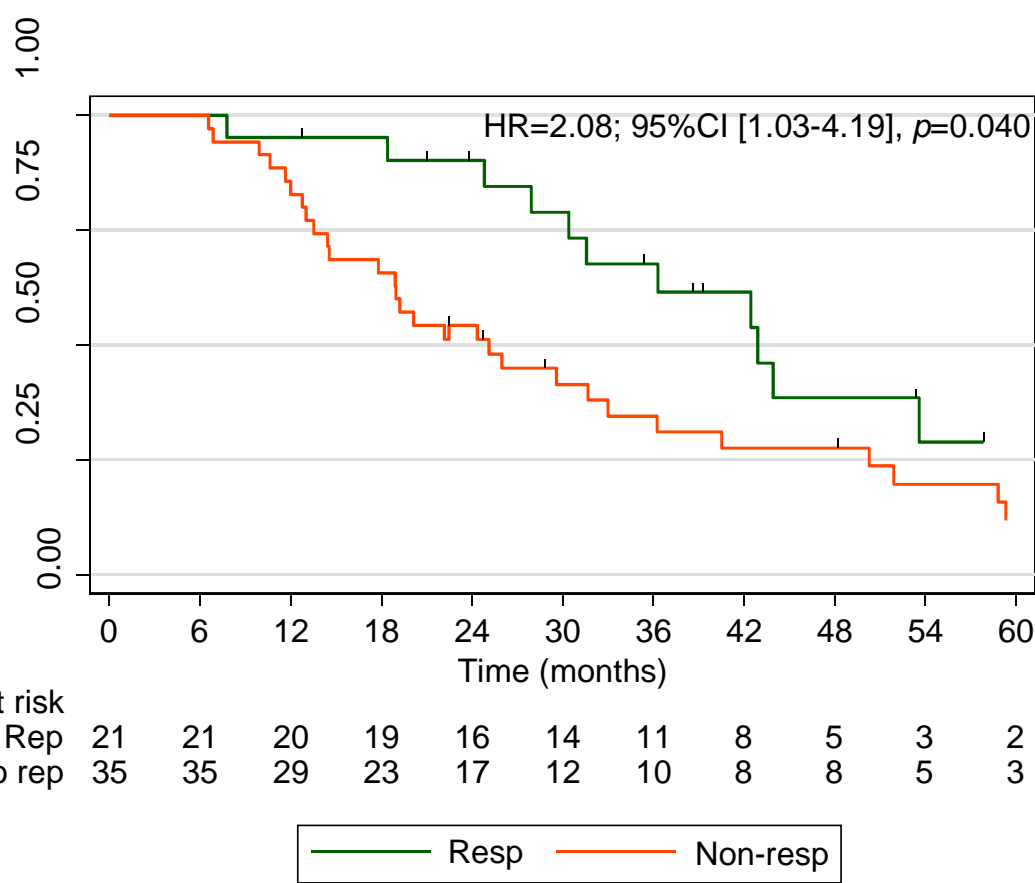

* OS was defined as the time between the date of first surgery to death. The Kaplan-Meier estimates of probabilities of $O S$ depending on the TRG pathological response were estimated for responders $(T R G 1,2,3)$ versus non-responders (TRG 4,5)

B. mTRG classification: responders (mTRG 1,2,3) versus non-responders $(4,5)$

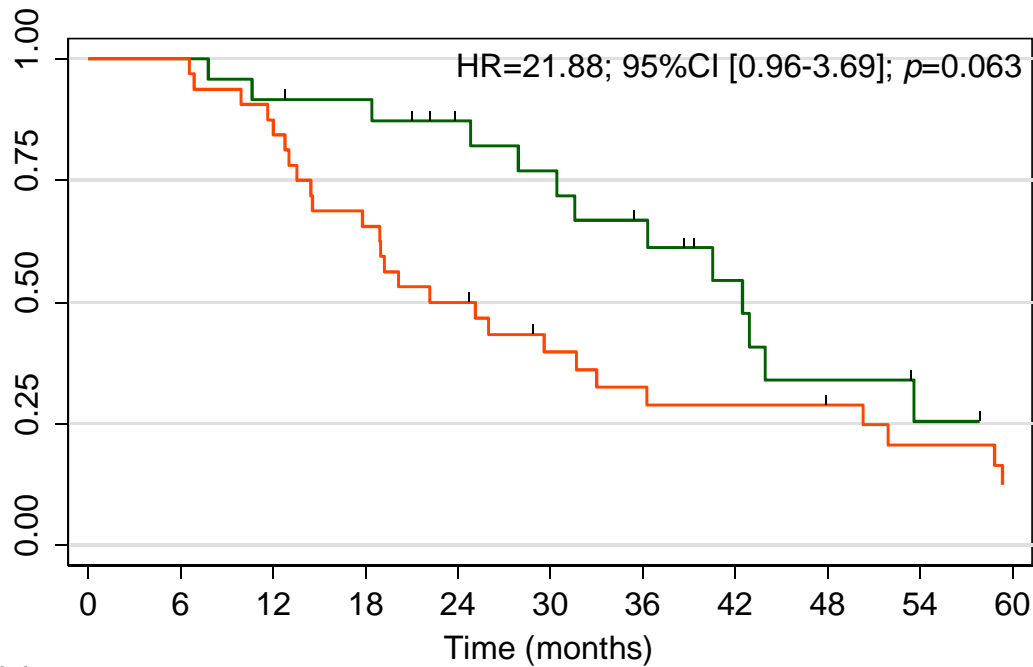

Number at risk

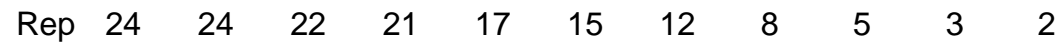

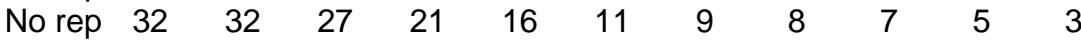

* OS was defined as the time between the date of first surgery to death. The Kaplan-Meier estimates of probabilities of $O S$ depending on the mTRG pathological response were estimated for responders $($ TRG $1,2,3)$ versus non-responders (TRG 4,5) 
C. Blazer classification: responders (Blazer 0,1) versus non-responders (Blazer 2)

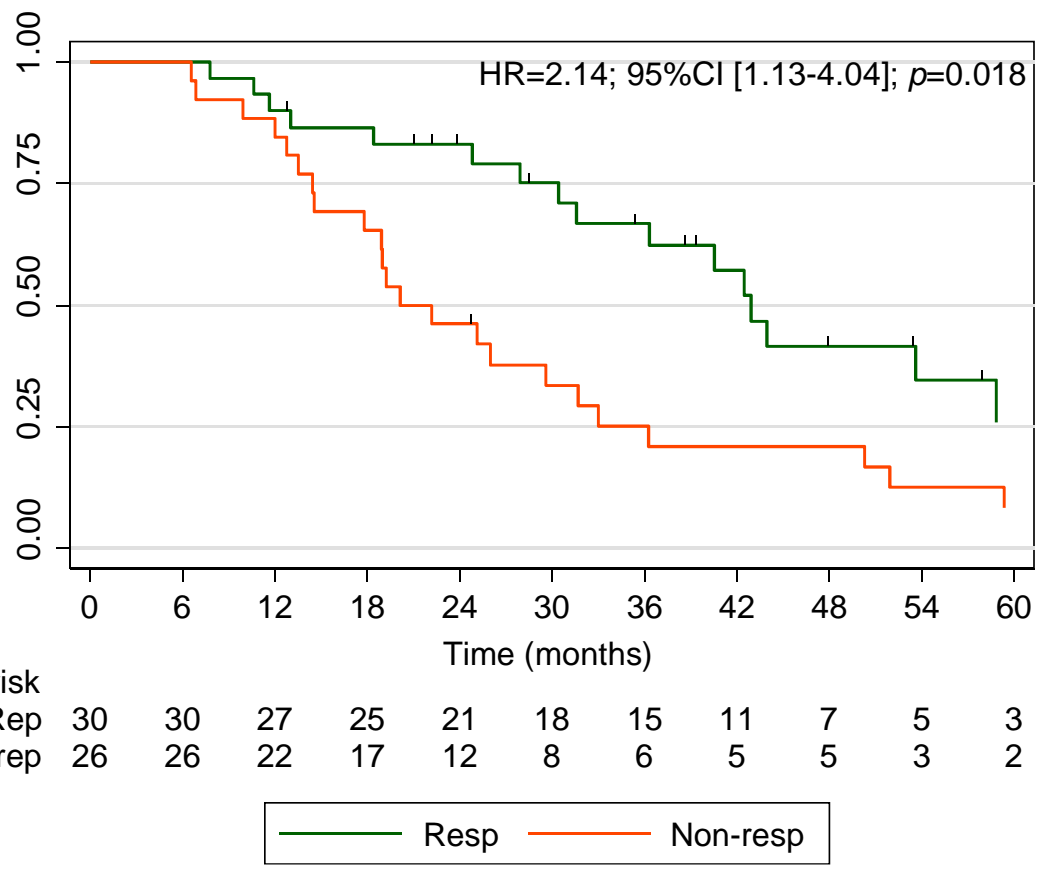

* OS was defined as the time between the date of first surgery to death. The Kaplan-Meier estimates of probabilities of OS depending on the Blazer pathological response were estimated for responders (Blazer 0,1) versus non-responders (Blazer 2) 